\title{
A Study of Cutter Number Adjustment at the Ohio State University Libraries
}

\section{Magda El-Sherbini and John C. Stalker}

\begin{abstract}
The authors conducted a study of cuttering practice at Ohio State University Libraries to determine the extent of effort presently devoted to the practice and to suggest changes that would result in less work without adversely affecting the public. They determined that there would be little deleterious effect if cuttering were limited to classes $M, N$, and $P$, while the effort involved would be halved.
\end{abstract}

\section{$\mathbf{T}$} ter numbers requires a substantial commitment of resources in copy cataloging. A recent OCLC Online Computer Library Center, Inc. (1994-1995, 4) research project report notes, "Cuttering is an expensive, time-consuming, and errorprone operation, and has never received as much intellectual attention as classification. For copy cataloging, the cutter number is the only item in the bibliographic record that routinely requires adjustment to ensure that the call number is unique and fits into the local shelf list. In many instances, except for cuttering, records could be automatically downloaded into the local system without manual processing." OCLC's research aims at developing an acceptable algorithm for automatic cuttering. Expert systems have also been suggested to help with cuttering (Drabenstott, Riester, and Dede 1992).

The Ohio State University (OSU) Libraries share this burden of adjusting cutter numbers in copy cataloging. In May 1995 library staff conducted a survey and analysis of cutter number adjustments to determine their extent and nature. Staff also explored whether changes could be proposed to lessen the burden without defeating the purposes of book number assignment and providing a unique call number, all while minimizing deleterious effects on whatever other purposes cutter numbers might serve.

\section{Historical Background}

Book numbers became an important issue in the 1870s. Two lengthy studies of book numbers appeared in the early 1980 s (Lehnus 1980; Comaromi 1981). Barden (1937) provides an excellent, brief history of early developments. Direct patron access to collections and the development of "close classification" to arrange books on library shelves made book numbers necessary to provide an arrangement within ultimate subclasses. Charles A. Cutter (1878), Melvil Dewey (1879), John Edmands ("Plan for Numbering," 1878, 38) and Jacob Schwartz (1878) all contributed

MAGDA El-Sherbini (melsher@magnus.acs.ohio-state.edu) is Head of Cataloging and JoHn C. STALKER (stalker.1@osu.edu) is Head of Information Services, Ohio State University Libraries, Columbus. Manuscript received May 7, 1996; accepted for publication July 8, 1996. 
to the early development of book numbers. Library Journal published a symposium titled "A Plan for Numbering" (1879). Jacob Schwartz, the librarian at the New York Apprentices' Library, developed the idea of mapping authors' names into numbers, and Cutter, Dewey, and Edmands contributed ideas and suggestions that resulted in the form of book number-a letter followed by a series of digits-now familiar to us as the cutter number.

Dewey originally preferred arrangement within ultimate subclass by date of accession, and W. S. Biscoe (1885), librarian at Columbia, urged a chronological arrangement at the Lake George ALA conference in 1885 . His date-letters later found their way into Cutter's Expansive Classification and Dewey's Decimal Classification. Cutter realized that later additions to the collection might make strict adherence to alphabetical order difficult to maintain without considerable effort or lengthy numbers. In that case, he wrote, "either the names can be renumbered ... or the precise alphabetical order can be disregarded. As very great accuracy is in this matter of little account, the latter course would generally be best." However, the distinction between the class number and the cutter number became blurred in some cases in order to provide an alphabetical list of subtopics, to enable autobiographies to precede biographies, to have translations follow originals, and for other purposes. Moreover, in an effort to make cutter numbers as brief as possible, the same author's name may be represented by different or fewer digits in a sparsely populated class than in a crowded class. Therefore, no simple formula can map an author's name into a number.

Because of the effort required to preserve shelflist order, Tomlinson (1932, 292) remarked, concurrently with Brown (1932), that "a veritable epidemic of libraries ... do not use the Cutter book number" in order to achieve savings of time and effort in the workroom. She further asked, "Are cutter numbers doomed?" For large libraries, she noted that the time and effort saved in the workroom might be shifted to patrons and shelvers. Therefore, librarians at the OSU libraries decided to measure the amount of time and effort dedicated to maintaining a strict order of cutter numbers in order to determine whether changes in current practice could decrease that time and effort.

\section{The Committee Charge}

The Cataloging Policy Advisory Council (CPAC) was charged with studying existing copy cataloging procedures to assess whether it was feasible to eliminate the review and adjustment of cutter numbers in producing copy cataloging records. A change in this procedure might reduce processing costs and improve productivity.

\section{METHODS}

CPAC produced a list of questions that was sent to the Cataloging Policy Board (CPB). CPB devised a survey and asked the head of Copy Cataloging to gather data on monographic records over a oneweek period.

Information gathered in the survey can be grouped into four general categories:

1. Class, language, date of publication, location, record type, or record level in which the cutter number was adjusted

2. Presence of cutter number

3. Type of cutter number

4. Reason for adjusting cutter number

A total of 1,046 survey sheets were gathered, and survey results were loaded into an Excel spreadsheet. The SAS statistical package was used to analyze the data and produce statistical tables.

\section{BACKGROUND ON THE EXISTING OSUL Shelflisting Policy}

The current call number policy for shelflisting is to review all call numbers both to verify their uniqueness and proper fit in the alphabetical order and to apply local practices.

It is assumed that it is important to keep the call numbers unique. Only strict alphabetical order under main entry on 
the shelves is in question and requires study. Local practices should be identified and compared with national standards and practices. If the two differ substantially, then the value of the local practices should be assessed.

Some examples of the differences between local and national practices are listed below.

\section{Translations}

Currently, whenever the Library of Congress (LC) does not provide a special scheme for translations, librarians at OSUL follow their own scheme. In the book Midaq Alley by Najib Mahfuz, for example, the cutter number for the translation from Arabic to English was changed in the OCLC record from OCLC PJ7846 A46 Z4813 to OSUL PJ7846 A46 Z481.

\section{BIOGRAPHIES AND AUTOBIOGRAPHIES}

OSUL policy for items for which LC slides the second cutter is to follow what is already established in the shelflist. In most cases this requires the addition of a third cutter for main entry, but a few places in the shelflist follow LC and use the sliding second cutter. If nothing has yet been established in the shelflist, OSUL policy is to add the third cutter. For example, in class $\mathrm{P}$, where tables VIIIa and IXa apply, OSUL prefers Z5 for autobiography and Z8 for biography and criticism. If there are several autobiographies, Z52, Z53, etc. are used. Z8 is followed by a cutter number for author of the biography or criticism. For example, the cutter number in the OCLC record for a biographical work on James Albert Michener was changed from OCLC PS3525 $119 \mathrm{Z73}$ to OSUL PS3525 I19 Z8 C5.

In this case the cutter number $\mathrm{Z73}$ in the OCLC record was changed to $Z 8$ with a third cutter, C5, added for the author of the biography.

\section{CRITICISM}

It is OSUL practice to add " 18 " to the cutter number for works of literary criticism. For example, the cutter number of
In Search of Centennial: A Journey with James A. Michener by John Kings was changed from OCLC PS3525 I19 C434 to OSUL PS3525 I19 C418.

\section{SELECTIONS}

It is OSUL local practice to add " 17 " to the cutter number if the book is an author's selected works. For example: the cutter number of the Selected Works of Henry Louis Mencken was changed from OCLC PS3524 E43 P912 to OSUL PS3524 E43 P817.

\section{The STUdy}

\section{Distribution aND CHARACTERISTICS OF THE SAMPLE}

A careful look at the tables of distribution and characteristics of the sample reveals that the sample is representative of the entire population of books cataloged in a year. The sample includes books from all languages, in all location libraries, dates of publication, and sources of cataloging (e.g., LC, member copy, etc.).

\section{ANALYSIS OF THE DATA}

As mentioned before, the size of the oneweek sample was 1,046 records. The statistics indicate that there were 694 records (66.34\%) that fit the shelflist with no adjustment to the cutter number. Two hundred eighty-eight records $(27.53 \%)$ were adjusted to fit the shelflist alphabetical order, and 64 records $(6.11 \%)$ were adjusted to fit OSUL local cataloging practices.

In analyzing these data, six questions were addressed on the distribution of changes and additions to the cutter. If the cutter number were no longer adjusted, we wanted to see what particular areas would be affected and what exceptions needed to be considered.

\section{To What Extent Was the Cutter Adjusted in Various Classes and What Was Adjusted?}

The range of adjustment in the main entry was between $5 \%$ and $55 \%$. In most classes, the cutter was adjusted to fit the shelflist alphabetical order. However in class $\mathbf{P}$, 


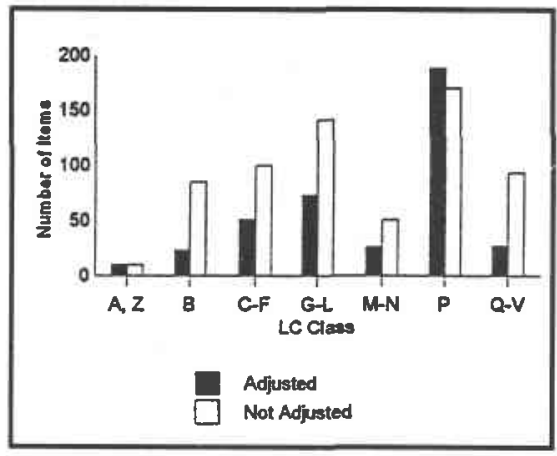

Figure 1. Cutter Adjustment by LC Class

especially PC, PL, PN, PQ, PR, and PS, most of the adjustments occurred because of OSUL local practices. These adjustments follow the OSUL translation tables and add the third cutter, the criticism, or the biography number. There were no major adjustments in the personal, geographical, and topical cutter except in class $P$, where the above adjustments were made (see figure 1).

\section{To What Extent Was the Cutter}

\section{Adjusted for Different Languages} and What Was Adjusted?

The changes occurred across all languages without focusing on a particular language. The range of changes in the main-entry cutter was from $3 \%$ to $55 \%$. Most of the changes were made to follow OSUL local practice. For example, in English-language records, $23 \%$ were adjusted to add the translation, third cutter, biography, or criticism number.

In Chinese-language materials, $55 \%$ were adjusted because the LC classification was modified frequently. As a result, adjustment was made to group materials together under the same subject headings with the established classification number (personal headings, geographic, and topical headings). Another reason is that for many Chinese materials, the main entry starts with the letters $C h$. This requires consultation of the shelflist to fit the cutter number. About $50 \%$ of the Chinese records required cutter adjustment because they were based on member copy, with various local cutter practices. The same applied to Japanese-language materials, for which $24 \%$ of the records were adjusted to accommodate local practices and proper order.

The remaining cutter changes occurred to fit the shelflist alphabetical order. In terms of geographical and topical cutters, there were no major changes or additions to the cutter number except to fit the shelflist alphabetical order.

\section{For Which Imprint Dates Was the Cutter Adjusted and What Was Adjusted?}

Proportionally, older materials (e.g., those printed before 1979) require more adjustment than post-1990 imprints. For example, in materials dated before 1979 , adjustments occurred in $43 \%$ of the records. In examining these records, we discovered that the majority of them were in English, in class PS, and for the TRI (Theater Research Institute) library. In post-1979 materials, adjustments were made in $57 \%$ of the records cataloged in this sample. Most of the adjustments in these records occurred without focusing on particular locations, classes, or languages.

We found that no major changes were made in topical and geographical cutter in any date of imprint (see figure 2).

\section{To What Extent Was the Cutter Adjusted for Different Locations and What Was Adjusted?}

Changes in the cutter happened across all location libraries. The range of changes in

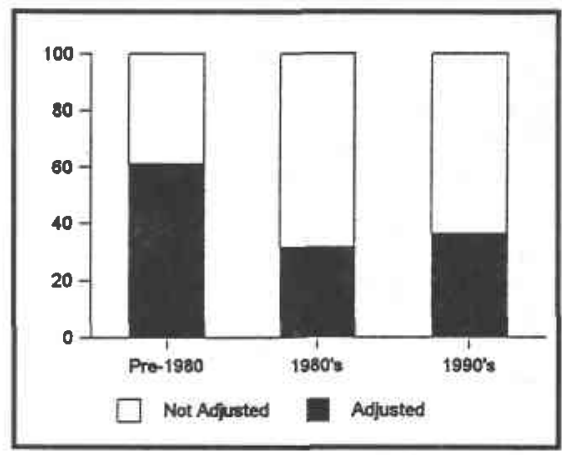

Figure 2. Percentage Adjusted by Date of Work 
the main cutter was $4 \%$ to $80 \%$. Some locations required many changes. For example, changes were made to $80 \%$ of records for the books housed in the East Asian Studies, for the reasons stated above.

The second-highest percentage of changes $(78 \%)$ occurred in records for items located in the TRI library. One reason for these changes is that many items cataloged for TRI are plays, which fall into the literature category, in which the cutter number is frequently adjusted to fit OSUL local practice.

Another reason for frequent cutter changes is the age of materials. Because many of the TRI materials are old and were cataloged much earlier, existing cataloging records call for modification of the cutter number to fit the shelflist order. For example, a cutter number of a play by Mabel Margaret Cowie Clark was changed on the OCLC record from OCLC PR6005 L32 H4 to OSUL PR6005 L36 H4. The reason for changing the author number is that the author number was established earlier at the OSUL shelflist as L36. This practice explains why the percentages of adjusting the cutter number in class PS $(47 \%)$ in the personal cutter and in the pre-1979 (43\%) books were relatively high.

The third-highest percentage of changes occurred in materials for the Map room. One reason is that most of the cutter numbers for map records had single digits; to make room for additional digits, the cutter number was expanded. For example, the cutter number of one map was changed from OCLC G876 L3 to OSUL G876 L34. In this case the cutter number fit the shelflist order, but another digit (4) was added to expand the cutter number for future titles starting with the letter $L$.

In $50 \%$ of the books housed in the music library, the cutter number was changed. One reason was that in the past, in addition to the composer number, the cataloging department used another cutter for the title of the book. Shelflisting policy later changed and no longer required use of the second cutter. This had an adverse impact on the shelflisting process, requiring fitting a single cutter into

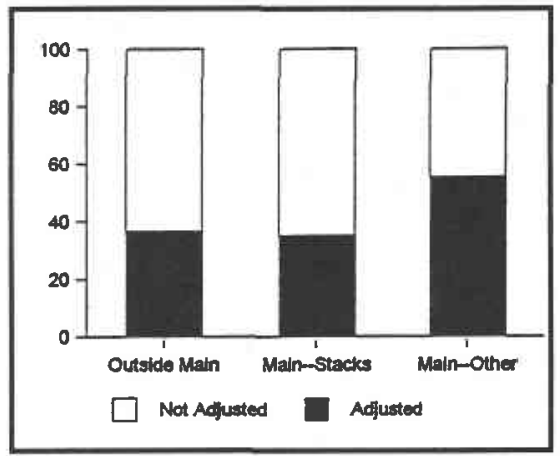

Figure 3. Percentage of Adjustment by Type of Location

a double cutter number. No major changes were needed for the geographic and the topical cutter number (see figure 3).

\section{In Which Record Types Was the Cutter Adjusted and What Was Adjusted?}

Record source tables indicate that the most changes in cutter number were made for records supplied by member libraries (29\%) followed by records provided by LC $(17 \%)$. There were no major changes in the geographic and topical cutter number.

\section{To What Extent Was the Cutter Adjusted for Different Record Levels and What Was Adjusted?}

There were changes in all record levels, but records that are encoded as levels $\mathrm{L}$ (which is a tapeload from RLIN to OCLC) and 7 (which is minimum-level cataloging done by LC) had the most changes in the cutter number (33\%). These were done to fit the shelflist order. Changes to records encoded level I (full LC record) were done to follow local practice.

\section{Some General Observations AND SUMMARY}

In the sample, the cutter numbers in 694 records (66\%) were accepted as is. In 288 records $(27.53 \%)$, the cutter numbers were adjusted to fit the shelflist alphabetical order, and in 64 records $(6.11 \%)$ the 
cutter numbers were adjusted to fit OSUL local practices. The following paragraphs will provide some explanation and examples of two types of change.

\section{Changing Cutter to Fit the Shelfiist Order}

As mentioned before, adjustments to the cutter numbers occurred in 288 records across class, language, location, and level of cataloging. These cutters were adjusted to keep the books on the shelves in alphabetical order and to facilitate browsing by patrons.

Some examples of changing the cutter to fit the shelflist alphabetical order are:

$\begin{array}{ll}\text { OCLC } & \text { OSUL } \\ \text { LB 2825 B428 } & \text { LB 2825 B39 } \\ \text { LB 2825 B434 } & \text { LB 2825 B4 } \\ \text { LB 2825 B44 } & \text { LB 2825 B44 } \\ \text { LB 2825 B55 } & \text { LB 2825 B5 } \\ \text { LB 2825 B678 } & \text { LB 2825 B67 } \\ \text { LB 2825 B722 } & \text { LB 2825 B73 }\end{array}$

These six examples were taken from the shelflist to examine how the cutter number was changed in records and why. In all six, the cutter numbers found in the OCLC records corresponded to those in the shelflist. No adjustments were needed.

Adjusting cutter for alphabetical order does not always produce desired results. Despite the efforts by the cataloging department, strict alphabetical order is not always achieved. Some books are not in order due to changes in the shelflist procedures and limitations of the old online system (LCS) in dealing with complicated cutter numbers (e.g., when the cutter number is more than three digits).

\section{Changing the Cutter Number to Follow OSUL Local Practice}

We also examined 64 records in which the cutter numbers were adjusted to fit OSUL local practice. Although OSUL primarily follows LC cataloging practices, it has also established local practices. Some of these were established to transcend the limitations of the old LCS system and are listed in the old LCS manual, while others were established for no discemible reason.
Comparison of OSUL local practice with LC practice indicates that OSUL does not completely follow LC practice. For example, OSUL does not cutter for collected prose works, polyglot language publications, periodicals, society publications, or serials. In cuttering for separate works, autobiography, and general works, OSUL uses its own cutter numbers. In general works, OSUL adds a third cutter for the main entry.

OSUL established its own translation numbers by modifying and expanding the LC cutter numbers. OSUL also expanded the use of the LC translation tables. LC did not expand the translation numbers because in some classification schedules, translations are designated with the caption "By language $\mathrm{A}$ to $\mathrm{Z}$ " and the date. In these cases, one cutters for the specific language by using .E5 for English, .F7 for French, etc. For example, OSUL changed the cutter number for an English-language translation of Erich Maria Remarque's work from OCLC PT2635 E68 I513 to OSUL PT2635 E68 I51.

In other cases, OSUL has also established another local practice that differs from other libraries, particularly LC. If an item is a part of something or an adaptation, OSUL adds .x17 to the cutter number. If it is a work of criticism, LC adds .$x 18$ to the cutter number. For example, the cutter number for Erich Maria Remarque by Richard Arthur Frida was changed from OCLC PT2635 E68 I5 to OSUL PT2635 E68 I518.

Although the number of records in which the cutter numbers have been adjusted for local practice is very small, it takes much time to determine if the book requires cutter change or addition. It also takes time to alter a number from the cutter to accommodate local practices. Because the LC practice of adapting uniform standards seems to satisfy their users, it seems reasonable to assume that this practice can be employed at the OSU Libraries.

\section{ADDITIONAL INFORMATION FROM OTHER LIBRARIES}

Additional information was gathered through an informal survey of other 
libraries posted to the AUTOCAT and CIC listservs. The following questions were asked:

- How do you ensure that the call number for each title is unique?

- Do you review every call number to fit the shelflist order, or do you accept call numbers as they are on the bibliographic record?

- If you don't do shelflisting, what is the impact on the access to the book by patrons?

Several librarians responded to the questions. Regarding the first question, one librarian mentioned that he added a digit to the OCLC call number to make it unique; two respondents indicated that they check the shelflist to make each title unique; while four indicated that they accept the call number unchanged.

Regarding the second question, the policy at four libraries is not to review every call number. One library reviews call numbers only for literary works. Two libraries review all books.

Regarding the third question, some librarians indicated that the importance of shelflisting varies from class to class. In literature, for example, alphabetical order is important, whereas in the sciences, date of publication is more important than alphabetical order.

\section{Final Recommendations}

As a result of the study, the CPAC made the following recommendations:

1. Continue to adjust cutter numbers in class "P," "M," "N" to put new items in online shelflist alphabetical order.

2. In all other cases, accept complete call numbers as they appear on copy

3. Add the date of publication for all materials, if not present in the call number.

4. Recommendations 1-3 address the use of call numbers present in copy. For original cataloging, follow the national standards for creating new records.

5. Duplicate call numbers:

a. When student shelvers find duplicate call numbers on books in the stacks (or when duplicates are found at any other point), they should be reported to supervisors, who should send the book with a note to the Cataloging Department to adjust the cutter number.

b. The Cataloging Department will also pursue other means of examining the rate at which duplicate call numbers occur in order to evaluate the impact of this change, e.g., generating duplicate call numbers report form OSCAR (OSUL's online catalog)

6. The issue of keeping conferences and editions together, by means of call number or cutter number, arose during the course of the study. This issue should be examined by the CPB and CPAC. Recommendations will be discussed with Heads of the Undergraduate and Department Libraries and Main Library Public Service Heads. Also, a separate proposal will be made in regard to Special Collections materials.

The recommendations were submitted to and accepted by the assistant director for technical services.

\section{Conclusions}

The study showed that a large percentage of the adjusted cutters were in classes $\mathbf{M}$, $\mathrm{N}$, and P. Because these are classes in which creative works are systematically ordered by cutter number to achieve effects more complex than mere arrangement by main entry within a specific class, they merit continued monitoring to achieve those special goals. Monitoring and adjusting the cutter number in other classes produces proportionally far fewer changes, and most of those changes merely maintain an already imperfect main entry arrangement within specific classes. The value added to call numbers by continuing to examine cutter numbers for all additions to the collection is insufficient to justify the time and effort required to maintain that practice. Limiting adjustment to classes $\mathrm{P}, \mathrm{M}$, and $\mathrm{N}$ means that only about two-fifths of added titles need to be examined for possible adjustment. Furthermore, class is an easily applied criterion for culling items for which 
further examination of the cutter number is necessary. The time saved on the other three-fifths of additions can be applied more productively to other cataloging activities.

\section{Works CrTED}

Barden, Bertha R. 1937. Book numbers. Chicago: ALA.

Biscoe, W. S. 1885. Chronological arrangement on shelves. Library journal 10: 24647.

Brown, Zaidee. 1932. More about cutter numbers. Library journal 57: 437.

Comaromi, P. 1981. Book numbers: A historical study and practical guide to their use. Littleton, Colo.: Libraries Unlimited.

Cutter, Charles A. 1878. Another plan for numbering books. Library journal 3: 248-51.

Dewey, Melvil. 1879. Arrangement on the shelves: First paper. Library journal 4: 117-20.

Drabenstott, K. M., L. C. Riester, and B. Dede. 1992. Shelflisting using expert systems. Classification research for knowledge representation and organization. Amsterdam: Elsevier Science Publishers.

Lehnus, Donald J. 1981. Book numbers: history, principles, and applications. Chicago: ALA.

OCLC Online Computer Library Center, Inc: 1994-95. Cuttering for the Library of Congress Classification. Annual review of OCLC research, 4-10.

Plan for numbering, with especial reference to fiction: A library symposium. 1879. Library journal 4: 38-47.

Schwartz, Jacob. 1878. A "combined" system for arranging and numbering. Library journal 3: 6-10.

Tomlinson, Anna Louise. 1932. Are cutter numbers doomed? Library journal 57:292.

\section{OCLC'S RETROSPECTIVE CONVERSION} OPTIONS MEET YOUR NEEDS

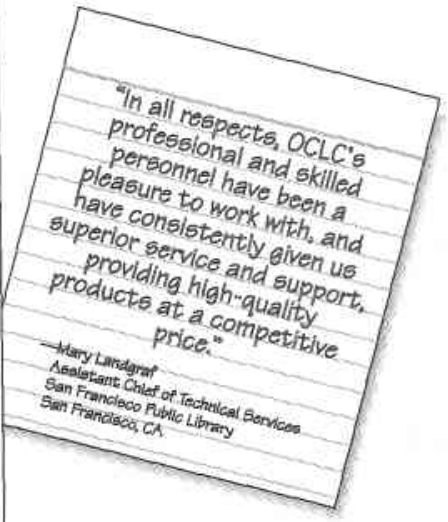

GET A FAST, ACCURATE RETROSPECTIVE CONVERSION WITH OCLC.

With over 20 years of experience, OCLC meets your needs with seven conversion options and a highly skilled staff. Approximately $95 \%$ of the records are found in the OCLC database, reducing the need for costly, timeconsuming creation of new records. Call today for more information. 